\title{
El estudio de la comunicación gubernamental: líneas de investigación y futuros desafíos
}

\author{
Belén Amadeo \\ Facultad de Ciencias Sociales, Universidad de Buenos Aires \\ belenamadeo@gmail.com
}

\section{Resumen}

Recibido: 14 de septiembre de 2016. Aceptado: 28 de octubre de 2016.

Los gobiernos son instituciones y, como tales, deben comunicarse con los ciudadanos de manera clara, planificada y coherente. Cada vez más los políticos comprenden que la comunicación es estratégica y debe conducirse de manera profesional. Ya no depende exclusivamente de la capacidad de oratoria de quien esté a cargo del Poder Ejecutivo ni de las sugerencias del partido en el poder. ¿Qué es entonces la comunicación gubernamental? ¿Cómo se relaciona esta comunicación con las relaciones públicas? ¿Cuáles son las líneas de investigación de esta disciplina? ¿Tiene herramientas específicas? ¿Cómo podemos clasificar a los gobiernos según su estilo de comunicación de gestión? ¿Qué papel juegan las redes sociales en todo esto? ¿Qué tenemos por delante en este terreno?

Palabras clave: Comunicación gubernamental, comunicación política, comunicación institucional, líneas de investigación.

\section{The study of government communication: lines of inquiry and future challenges}

\begin{abstract}
Governments are institutions and, as such, must communicate with citizens in a clear, organized, and coherent fashion. With greater frequency, politicians are beginning to understand that communication is strategic and therefore must be conducted professionally. That is, it no longer depends exclusively on the executive's oratory power nor on the reigning political party's own recommendations. What, then, is government communication? How does it relate to public relations? What lines of inquiry are needed to approach it? Does it have specific tools? Can we classify governments according to their style of communication? What role do social media play in all this? And what path lies ahead in this area?
\end{abstract}

Keywords: government communication, political communication, institutional communication, lines of inquiry 


\title{
O estudo da comunicação governamental: linhas de pesquisa e futuros desafios
}

\begin{abstract}
Resumo
Os governos são instituições e, como tais, devem se comunicar com os cidadãos de forma clara, planificada e coerente. Cada vez mais, os políticos compreendem que a comunicação é estratégica e deve ser conduzida de forma profissional. Já não depende exclusivamente da capacidade de oratória de quem esteja encarregado do Poder Executivo nem das sugestões do partido no poder. O que é então a comunicação governamental? Como se relaciona esta comunicação com as relações públicas? Quais são as linhas de pesquisa desta disciplina? Existem ferramentas específicas? Como podemos classificar aos governos segundo seu estilo de comunicação de gestão? Que papel jogam as redes sociais em todo este assunto? Que tenemos por diante neste terreno?

Palavras chave: comunicação governamental, comunicação política, comunicação institucional, linhas de pesquisa.
\end{abstract}

\section{Comunicar desde el gobierno}

Tal vez por error o desinterés, tradicionalmente la comunicación gubernamental fue vista durante muchos años como la hija menos glamorosa de la comunicación política. Las investigaciones de comunicación política en general solían centrarse en la comunicación electoral, esto es en las campañas, en la batalla por los cargos, en el tratamiento de las encuestas y en los efectos que estas puedan lograr en términos de votos y de imagen en el público.

La comunicación gubernamental, por su parte, apunta a otros objetivos. Noguera (2005) afirma que es un tipo de comunicación menos espasmódica y más sostenida, menos heroica, menos centrada en grandes discursos y más en la gestión. En este contexto, la conexión entre las relaciones públicas y la comunicación de gobierno existe y es clara. La misma definición de esa profesión acerca directamente ambas disciplinas.

El término relaciones públicas ha sido definido de muchísimas maneras. Ante tanta diversidad, en febrero de 2012 la Sociedad de Relaciones Públicas de América (PRSA, por sus siglas en inglés), organismo que nuclea a los profesionales del sector en los Estados Unidos, llevó adelante una votación mundial para elegir una definición consensuada de este oficio entre los profesionales de todo el planeta. Para ello recibió la colaboración de sus pares en otros países. El 46,4\% de los participantes (671) votó por la definición ganadora: "Las relaciones públicas consisten en el proceso estratégico de comunicación que construye relaciones mutuamente beneficiosas entre las organizaciones y sus públicos" (Public Relations Society of America, 2012).

Es importante notar que la definición incluye conceptos como "construir relaciones beneficiosas" o "entendimiento mutuo". Asimismo, se habla de organizaciones sin especificar si se trata de entes públicos o privados. Esto capta la idea de que todas las 
instituciones, tanto las privadas como las públicas, necesitan comunicarse de manera organizada, estratégica y coherente.

La definición de los interlocutores, el mensaje que se les enviará, las herramientas y las acciones elegidas para transmitir ese mensaje y los plazos a considerar, son todos elementos esenciales en la construcción de una imagen institucional exitosa. La comunicación es una herramienta de gestión y, como tal, debe ser planificada, debe estar alineada con los objetivos de la organización y debe asignársele un presupuesto específico con tareas concretas y con su consiguiente evaluación. En el sector privado esta comunicación institucional se llama "comunicación corporativa" y en el sector público es "comunicación gubernamental".

En este trabajo atenderemos a la comunicación de gobierno, entendiendo que el Poder Ejecutivo es la institución que mejor debe comunicarse con los ciudadanos por ser la institución pública más importante de cualquier país.

\section{Definición y funciones de la comunicación gubernamental}

¿Qué es, entonces, la comunicación de gobierno? Según Juan José Solís Delgado (2010) el ámbito de la comunicación gubernamental está bien acotado: se circunscribe solo a la gestión y la administración pública. Más aun, dado que la comunicación gubernamental supone un ejercicio que determina la agenda de la gestión de instituciones, actitudes y procesos, debería ser tratada como una política pública en sí misma.

Sin llegar a plantearlo en estos términos, María José Canel y Karen Sanders definen la comunicación de gobierno como aquella que se elabora desde un Poder Ejecutivo. Para las autoras, la comunicación gubernamental es "la comunicación que implica el desarrollo y actuación de una institución política con función ejecutiva. Esto abarca desde la comunicación de un presidente, de un primer ministro o de un ministerio hasta la comunicación de una alcaldía, una concejalía o de una consejería de un gobierno autonómico" (Canel \& Sanders, 2010, p. 19).

Por su parte, Mario Riorda define la comunicación gubernamental como "un método a través del cual un gobierno democrático intenta hacer explícitos sus propósitos u orientaciones a la opinión pública para obtener apoyo o consenso en el desarrollo de sus políticas públicas" (Riorda, 2006, p. 7). Si bien coincidimos con la definición planteada por Canel y Sanders, la propuesta por Mario Riorda resulta más adecuada porque expresamente enmarca la comunicación de gobierno en un contexto democrático. La comunicación de un gobierno dictatorial no supone comunicación sino información: es propaganda.

En este contexto veamos cuáles son las funciones de la comunicación política en democracia. Sobre este tema Lucien W. Pye (1991) entiende que el flujo dominante de la comunicación política se convierte en la fuerza crucial para la definición y expli- 
cación de lo que es significativo en política en un momento dado. Más aun, el autor sostiene que la vida política en cualquier sociedad de masas es imposible sin métodos establecidos de comunicación política. Ninguna persona sola puede discernir directamente todas las actividades que constituyen el proceso político; líderes y seguidores dependen en igual medida de la función de comunicación para conocer cuáles son, según otros, las noticias políticas del día. Por esto Rosalía Winocour (2000) sostiene que la comunicación política debe:

- contribuir a identificar los problemas nuevos a través de los políticos y de los medios;

- abrir canales de participación ciudadana para que la jerarquía y legitimidad de los temas de la agenda política resulten de un juego de negociación y,

- marginar las cuestiones que han dejado de ser objeto de conflictos o respecto de los cuales existe un consenso temporal.

Todas estas funciones de la comunicación de gobierno son compatibles entre sí y deben estimularse. Como se ve, la comunicación gubernamental es más relevante para el sistema político que el mero cuidado de la imagen del gobernante. La comunicación gubernamental es una herramienta de gestión que va más allá y ayuda a legitimar el gobierno de turno.

\section{Comunicación gubernamental y campaña permanente}

Debido a esta necesidad de legitimar constantemente todas las acciones de gobierno hay autores que sostienen que la comunicación gubernamental pasó de ser un oficio esporádico limitado a las ocasiones en las que los líderes debían dirigirse al público a través de sus discursos, a convertirse en lo que llaman "campaña permanente" (Noguera, 2005; Amado \& Amadeo, 2012). Una vez que Pad Caddell acuñó el término "campaña permanente" en un memo al entonces presidente electo Jimmy Carter en 1976, quedó claro que se esperaba que la comunicación de gobierno fuera la continuación de la campaña electoral (Ornstein \& Mann, 2000).

Durante años la idea [de 'campaña permanente'] fue usada por la comunidad política para referirse al uso que el gobierno da a este instrumento para construir y sostener el apoyo popular. Presidentes y parlamentarios han usado los recursos y oportunidades que les brindan sus cargos de manera cada vez más intensa y creativa para consolidar sus posibilidades de reelección. Pero el concepto de 'campaña permanente' ha sido particularmente fructífero en describir la creciente importancia que las estrategias, tácticas y recursos de campaña tienen en todos los aspectos de la vida pública. Candidatos a la presidencia y al congreso ahora están en una campaña perpetua. [...] 
El límite entre la campaña electoral y el gobierno se desdibuja, corriéndose cada vez más hacia la campaña (Ornstein \& Mann, 2000, p. vii).

A la hora de explicar este concepto, Hugh Heclo (2000) dice:

Llamándola "la ideología de nuestra era", Blumenthal describió la campaña permanente como una combinación de elaboración de imagen y cálculo estratégico, lo que convierte a la gestión de gobierno en una campaña perpetua y convierte al gobierno en un instrumento diseñado para mantener la popularidad de un funcionario electo (Heclo, 2000, p. 2).

Canel (1999) agrega a esto el concepto de que esta necesidad de apoyo permanente por parte de los ciudadanos es consecuencia de dos cosas: por un lado, del creciente desarrollo de los medios de comunicación que ha permitido mayor acceso del público a las acciones de gobierno y, por otro, de la posibilidad real que tiene el gobierno de informar algo a los ciudadanos en tiempo real a través de los medios. Esta doble oportunidad hace que la gestión de gobierno esté constantemente sometida a publicidad. "Como consecuencia, la 'campaña permanente' consiste en hacer que el presidente (o el líder gubernamental) sea alguien muy visible, público, que ocupe espacio en los medios de comunicación, de forma que sea claramente reconocible e identificable por los votantes" (Canel, 1999, p. 103).

Pese a la claridad con la que ambos autores explican la idea de campaña permanente, disienten con esa idea. Heclo (2000) y Canel (2007) entienden que no es lo mismo la comunicación electoral que la comunicación gubernamental. Esto es así porque la lógica y los objetivos del candidato son diferentes, así como su público.

La comunicación de una institución política no se puede plantear en términos de campaña pues hay diferencia entre batallar por un triunfo electoral y gobernar [...] La campaña se propone el voto y el Gobierno, gobernar. Por eso, mientras que la campaña es adversarial (es una competición pues solo uno gana), la comunicación de Gobierno ha de buscar la colaboración pues el ejercicio del Gobierno requiere oír muchas partes, consultar, negociar y llegar a compromisos. La campaña es persuasión y venta, mientras que el Gobierno es deliberación y enseñanza. Por tanto, concluye Heclo (2000), cuando un Gobierno se vicia de las actitudes de la campaña, está perdiendo la visión del largo plazo. Y, en consecuencia, concluyo yo, está perdiendo la perspectiva que da la planificación estratégica de la comunicación (Canel, 2007, p. 158).

Pese a estas claras diferencias teóricas, en la actualidad ocurre que muchos de los gobiernos latinoamericanos utilizan su comunicación gubernamental para extender sus mandatos. Tal vez en los países centrales estas diferencias entre la comunicación gubernamental y electoral se den de manera contundente y empíricamente comprobable, pero en los países de esta región la función de las comunicaciones gubernamental y electoral muchas veces suele confundirse (Ponce \& Rincón, 2013).

A modo de ejemplo, podemos citar la publicidad electoral elaborada para ambos mandatos de Cristina Fernández de Kirchner. Esas campañas mantuvieron el estilo de la publicidad gubernamental emitida durante las gestiones kirchneristas previas, con 
lo que logró reforzar su posicionamiento como candidata en las elecciones (Amado, 2011). En estos casos "la comunicación gubernamental apuntaló la comunicación electoral, como se ve en el aumento del presupuesto en los años de elecciones y en que ambas campañas tienen el mismo objetivo de exaltar las virtudes de los gobernantes" (Amado, 2011, p. 12) antes que informar de las políticas públicas a los gobernados.

Asimismo, cuando un presidente busca su reelección puede incluso hacer proselitismo a través de la comunicación de gobierno. Mario Riorda (2011) es tajante cuando sostiene que las elecciones se ganan con la comunicación de gobierno, porque este goza de ventajas por sobre los partidos de la oposición, que deben restringirse a los plazos y espacios electorales (Amado \& Amadeo, 2012).

\section{Relaciones públicas y comunicación gubernamental}

Si volvemos sobre el tema planteado en la introducción, corresponde que analicemos brevemente qué diferencias plantean la comunicación de una institución privada, como una empresa, y de una institución pública, como un gobierno. María José Canel y Karen Sanders (2010) describen algunas complejidades y oportunidades de la comunicación de un gobierno y resumen las consideraciones que diversos autores realizan sobre esta cuestión.

Entre esas complejidades, destacan que los gobiernos actúan en contextos políticos con mandatos que tienen una duración determinada, mientras que una empresa puede diseñar su identidad corporativa para un plazo más largo. Esto afecta tanto a la elaboración del plan de comunicación de gobierno - que debe pensarse para el mediano y el corto plazo-, como a la selección del personal, que suele ser elegido no en relación con los objetivos institucionales sino por el grado de confianza que ese individuo despierta en el gobernante.

Asimismo, las autoras advierten que el sistema político marca condicionantes clave: no es lo mismo comunicar en un sistema presidencialista que en un parlamentarismo, ni es igual comunicar en un país acostumbrado a gobiernos de coalición que en donde los gobiernos son de un solo partido. Tampoco es lo mismo comunicar en un país con sistema multipartidista que en un país bipartidista. Sostienen que:

La orientación al bien público que es propia de todo gobierno encuentra su expresión regulatoria en la legislación sobre la libertad de información así como en los requerimientos de transparencia y apertura que esta lleva consigo: se exige que las instituciones públicas den cuenta a sus públicos de lo que hacen (Canel \& Sanders, 2010, p. 13).

Este elevado escrutinio público es ajeno al sector privado y se produce, además, en un contexto de elevada mediatización, lo que convierte a la comunicación política en "una pugna de los políticos y de los comunicadores por ganar la batalla de la 
agenda en los medios" (Canel \& Sanders, 2010, p. 13). Más allá de estas diferencias sustanciales, las autoras sostienen que la comunicación gubernamental y las relaciones públicas convergen en algunos puntos de investigación, a saber:

- relaciones de los gobiernos con los medios de comunicación;

- campañas de comunicación gubernamental (issue management);

- comunicación interna en la administración pública;

- perfiles y habilidades profesionales de los comunicadores gubernamentales;

- comunicación de crisis de un gobierno ante catástrofes naturales, escándalos y desastres (Canel \& Sanders, 2010, p. 22).

Tanto es así que algunas de las técnicas empleadas en comunicación corporativa -la gestión de prensa, la publicidad institucional, el manejo de crisis y la identidad visual, entre otras- se convirtieron en recursos corrientes de la comunicación gubernamental. Algunos gobiernos, particularmente los latinoamericanos, dan prioridad a herramientas de comunicación unidireccionales que demandan altos presupuestos, lo que incluso da ventaja en la comunicación pública al gobierno por sobre la comunicación de la comunidad y de los demás partidos políticos (Amado \& Amadeo, 2012; Rincón, 2008).

El uso de las relaciones públicas no implica solamente un plan intensivo de emisión de mensajes sino que, bien entendidas, pueden contribuir al intercambio con los diversos públicos. El riesgo reside en que el gobierno de turno se aproveche del poder que ejerce y que, en su afán de legitimar su imagen perpetuamente, caiga en una gestión de la comunicación gubernamental asimétrica que lesione la igualdad de fuerzas del juego democrático (Amado \& Amadeo, 2012).

\section{Algunas líneas de investigación de la comunicación política}

La comunicación de gobierno como objeto de estudio está en proceso de configuración. Así, podemos encontrar algunas áreas o temas ya muy trabajados en relaciones públicas o comunicación corporativa y que, poco a poco van tomando entidad propia en esta disciplina. Algunas de ellas son los estudios de casos, el análisis de las herramientas de comunicación utilizadas, los estilos de comunicación gubernamental, el manejo de crisis, la comunicación local, la relación entre la comunicación de gobierno y los medios de comunicación, aplicación de las redes sociales y, por supuesto, el desarrollo teórico del concepto y sus características. Veamos algunos de ellos. 


\section{Técnicas y herramientas de comunicación gubernamental}

A la hora de evaluar los planes de comunicación gubernamental debe analizarse el diagnóstico inicial del que parten, los objetivos planteados, la estrategia propuesta, los mensajes y públicos objetivos definidos, el calendario y cronograma de actividades previstas y los medios de control y evaluación establecidos para medir la eficacia del plan (Minutella, 2010). No obstante, la investigación en comunicación de gobierno suele centrarse principalmente - por no decir exclusivamente- en las herramientas utilizadas por los políticos para hacer llegar su mensaje a la ciudadanía. Esto es así porque en América Latina la comunicación de gobierno se ha consolidado como un campo profesional importante, que cuenta con presupuestos crecientes y demanda cada vez más profesionales y especializadas.

Más aun, como vimos antes, en la mayoría de los casos se detecta que la comunicación presidencial adoptó un modelo de comunicación que integra recursos publicitarios y técnicas de relaciones públicas, de uso corriente en los ámbitos corporativos pero de reciente incorporación en las instituciones públicas.

\footnotetext{
Varios textos sobre la comunicación de gobierno coinciden en identificar intensas campañas de promoción de la figura del mandatario y de difusión de sus actos de gobierno. Se trata, casi siempre, de técnicas de la comunicación corporativa, tales como la gestión de prensa, la publicidad institucional, el desarrollo de sistemas de identidad visual, el monitoreo de imagen del gobernante, que se convirtieron en recursos corrientes de la comunicación gubernamental (Amado \& Amadeo, 2012).
}

Trabajos previos sobre la comunicación de los gobiernos de Néstor Kirchner y Cristina Fernández (2003-2015) identificaron un uso estratégico de las técnicas de relaciones públicas, que se observa en los organismos públicos con igual intensidad (Amado \& Amadeo, 2014). En una investigación planteada por Amado y Amadeo (2012) se propuso un análisis de la comunicación pública del gobierno desde los marcos teóricos de la comunicación institucional. Las autoras reflexionan acerca de los modelos de comunicación pública y, a partir de ahí, se analizan las implicancias que tiene su aplicación en el ámbito público de un modelo que habitualmente se ha utilizado en el campo empresarial. Asimismo, analizan que, por tratarse de una comunicación de construcción de imagen o de marca, los objetivos de la comunicación corporativa no necesariamente coinciden con el principio de publicidad de actos de gobierno.

Cuando un gobierno elige un esquema de comunicación totalmente empresarial, los medios pasan a ocupar el lugar de meros difusores de la información oficial, perdiendo su rol de interlocutores del poder. En casos así, la ciudadanía también pierde la posibilidad de interacción porque la abundancia de mensajes, antes que facilitar, obtura los canales de diálogo. La versión oficial es la que predomina en la medida en que cuenta con un presupuesto difícilmente equiparable por otros actores sociales para comunicar sus posiciones (Amado \& Amadeo, 2012). 
El nuevo esquema de comunicación utiliza un complejo sistema de canales articulados para llegar a distintos públicos, en el que se priorizan las herramientas de comunicación masiva tradicionales por sobre las que van dirigidas a públicos específicos. Amado y Amadeo (2012 y 2014) destacan algunos de ellos:

Publicidad. La difusión masiva de los mensajes de gobierno es el eje principal de la estrategia comunicacional y lleva la parte principal del presupuesto (Amado, 2010). La producción de las piezas publicitarias suele ser de altísima calidad y utiliza formatos de publirreportajes o documentales que superponen lo propagandístico con lo informativo desde un discurso emotivo (Amadeo, Amado \& Aruguete, 2013).

Producción de material informativo propio. Se busca producir material institucional de modo profesional (Starke \& Amadeo, 2010). Ese material se publica en múltiples canales del gobierno y de sus organismos (web, revistas institucionales, boletines, etc.) y se distribuye a los medios. Todo acto presidencial, declaración, presentación pública o evento es cubierto por un equipo de prensa que lo procesa y distribuye rápida y eficientemente a través de su web institucional y de las redes sociales.

El material informativo ofrecido a la prensa es de alta calidad y muy profuso (Amado, 2010). Este sistema implica que la actividad gubernamental es exclusivamente conocida a través del material original generado por el gobierno a través de los medios estatales. En el caso argentino, sin ir más lejos, esos medios son los únicos autorizados a cubrir actos oficiales.

Patrocinio, celebraciones, exposiciones y eventos. Otra característica de la comunicación que destacan las autoras es el auspicio de espectáculos y artistas populares. Los gobiernos también pueden fomentar activamente la producción de contenidos de cine y televisión a través de las áreas de educación y de cultura. El patrocinio supone la concesión de una ayuda económica o de otra clase a un evento, actividad, persona u organización con fines publicitarios y de difusión de marca (Amado \& Castro, 1999). De este modo el gobierno queda asociado a los espectáculos que patrocina.

En consonancia con la estrategia de patrocinios, se intensifican las celebraciones patrias, los eventos artísticos y actos conmemorativos con sus respectivos sitios web informativos. Más aun, a las clásicas efemérides patrias se agregan nuevas celebraciones que se amenizan con actos oficiales y recitales populares con fuertes campañas de difusión y despliegue de recursos escénicos. Tal como recomendaba Jean-Marie Domenach, se recurre a un despliegue de estandartes, ornamentos, divisas, desfiles, música, fuegos artificiales, "proyectores y antorchas que aumentan la fascinación" (Domenach, 1986, p. 75).

Marca país, la identidad visual. La identidad institucional es una técnica muy usada por los gobiernos. Sostiene Norberto Chaves que "la comunicación de la marca es un capítulo importante de la gestión corporativa y de producto, y se ha extendido a 
ámbitos tradicionalmente ajenos a toda consideración mercadológica" (Chaves, 2011, p. 7). Tal es el caso de la marca país. El autor afirma que esto se potenció en América Latina dentro del marco de los esfuerzos que están realizando sus países por obtener un mejor posicionamiento en los mercados internacionales, buscando un signo gráfico que identifique y sinergice todas las comunicaciones promocionales (Chaves, 2011).

Dependiendo del país, algunos gobiernos han desarrollado un complejo sistema de identidad visual tanto para el nombre de cada institución como para las dependencias y programas.

También se utiliza el proceso de branding, entendido como la "actividad o plan de actuaciones destinado a instalar en las audiencias una lectura diferenciada y notoria y valiosa de una entidad" (Chaves, p. 105) por el cual se bautizan leyes, decretos y resoluciones con nombres simbólicos (Fútbol para todos) o con siglas que tengan pregnancia (SUBE, i.e. Sistema Único de Boleto Electrónico).

Relaciones con la comunidad. Las relaciones con la comunidad son las tácticas comunicacionales que llevan a mejorar la relación que la organización tiene con la comunidad que la rodea. Los gobiernos hacen un fuerte trabajo con las organizaciones de base, logrando atemperar la protesta social en gran medida. En esa línea se desarrollan varios programas de asistencia a los sectores sin contención institucional, como planes sociales para desocupados o jubilación para individuos por fuera del sistema de aportes (Amado, 2011, p. 8).

Relaciones con los grupos de interés. La gestión de intereses frente al gobierno, amparado en el derecho constitucional para peticionar, consiste en mantener y desarrollar buenas relaciones creando canales y espacios para lograr consensos y acuerdos específicos entre instituciones públicas y privadas. Es fundamental que los gobiernos estén abiertos a escuchar las voces de diferentes grupos de interés. Algunos, de hecho, logran implementar políticas públicas con el apoyo explícito de esos grupos.

Estas herramientas enumeradas por Amado y Amadeo (2012) y algunas otras, propias del manejo de las relaciones públicas de una empresa, hoy son habituales en la comunicación gubernamental.

\section{Estilos de comunicación gubernamental}

Una línea de análisis de la comunicación gubernamental interesante y no muy desarrollada implica la clasificación de estilos. Una forma de ordenar estos estilos es seguir un eje que va de un sistema de comunicación totalmente abierto a uno totalmente cerrado, con todas las variantes intermedias posibles (Amadeo, 2014). El grado de apertura o cerrazón del esquema comunicacional de un gobierno está dado por el comportamiento de las siguientes nueve variables: enunciador, papel asignado a los medios de comunicación masiva, vocero, destinatario, discurso, enfoque, comu- 
nicación de los ministerios, producción de recursos y, finalmente, uso de TIC y redes sociales.

Comunicación gubernamental abierta. La comunicación gubernamental "abierta” entiende que los medios de comunicación son los actores principales de la comunicación gubernamental en tanto que funcionan como instituciones que median entre el gobierno y la opinión pública. Es a través de estos como el gobernante se comunica con los gobernados. Supone, como Swanson (2003, p. 10), que "al tener una audiencia masiva a nivel nacional, la televisión se ha convertido en una considerable fuerza de configuración de la opinión pública y en un importante intermediario entre los dirigentes y líderes políticos y el público en general".

Algunas de las prácticas propias de la comunicación gubernamental bajo este esquema son conferencias de prensa, entrevistas exclusivas y contactos con periodistas en actos públicos. Estos métodos de comunicación suponen la posibilidad por parte de los medios de hacer preguntas y plantear objeciones a las palabras del presidente. Y esto se relaciona directamente con el siguiente punto a considerar: el destinatario. En un sistema de comunicación abierta, el líder se dirige tanto a públicos neutrales como a públicos amigos y enemigos. Los considera ciudadanos racionales y votantes informados.

El vocero es, en este esquema, una persona activa y presente, bastante conocida por el público masivo. Es el interlocutor por antonomasia ante los medios de comunicación y tiene toda la autoridad del presidente para hablar por él. En cuanto al resto de los ministerios, la postura de la comunicación abierta es que cada dependencia estatal maneja su comunicación de manera independiente o, en su defecto, con una coordinación que busque sacar el máximo provecho de la difusión de la gestión de todas las áreas sin intervención de la presidencia en los contenidos ni en los formatos de esas comunicaciones ministeriales. Si bien no puede evitar algún manejo dramatizante del discurso, es cierto también que el esquema de comunicación abierto busca con denuedo presentar los temas con un enfoque más tematizado utilizando un discurso de consenso y de análisis de los datos para explicar la lógica de las políticas a seguir.

Como últimas dos características, todo gobierno elabora su material de difusión, pero en una comunicación abierta el gobierno no limita sus fuentes a su propia producción ni limita la presencia de otros medios en actos oficiales. En cuanto al uso de las TIC, un sistema abierto de comunicación gubernamental permite comunicación 2.0, es decir comunicación de doble vía en la que los ciudadanos pueden opinar sobre cualquier asunto sin ningún tipo de censura. El mejor sistema para lograr esto son las redes sociales.

En términos institucionales, la debilidad de mantener una política abierta pura reside en que se quita el foco a la función de control del poder legislativo: los medios se 
autoinstituyen como contrapoder, como evaluadores de las políticas públicas, a la vez que las conferencias de prensa fijan la atención de los ciudadanos en la coyuntura y no tanto en el largo plazo (tabla 1).

Tabla 1. Características de la comunicación gubernamental abierta y cerrada.

\begin{tabular}{lll}
\hline Enunciador & Comunicación abierta & Comunicación cerrada \\
\hline Papel de los MCS & Medios de comunicación & Presidente \\
\hline Vocero & Interpretación Intermediación & $\begin{array}{l}\text { Espejo. Transmisión literal. } \\
\text { Canalizadores de mensajes }\end{array}$ \\
\hline Destinatario & Activo y presente. Conocido. & Pueden ser los ministros \\
\hline Discurso & Toda la población & $\begin{array}{l}\text { Presidente. El vocero oficial es } \\
\text { desconocido para la opinión pública }\end{array}$ \\
\hline Enfoque & Ciudadanos racionales & Amigos y enemigos \\
\hline Comunicación de los ministerios & De consenso & Masa \\
\hline Producción de recursos & Tematización & De batalla \\
\hline Uso de TIC y redes sociales & Independiente o coordinada & Dramatización \\
\hline
\end{tabular}

Fuente: Amadeo, 2014.

Comunicación gubernamental cerrada. Muchas son las diferencias del sistema de comunicación cerrado con el anterior. En primer lugar, el protagonista de la comunicación cerrada es el gobierno. Es este el que impone las reglas de juego para limitar el papel de intermediadores de los medios. El gobierno se dirige directamente a la población, ya sea desde los medios oficiales, ya sea desde actos públicos cuyos discursos se refieren al tema que el gobernante quiere imponer en la agenda, sin necesaria referencia al asunto que haya convocado al acto.

Los medios de comunicación tradicionales, así como también las nuevas tecnologías, son meros repetidores de los discursos presidenciales, sin posibilidad de discutirlos ni de cuestionarlos. La figura del vocero oficial queda completamente difusa porque el mismo presidente ocupa ese papel y es muy activo en ese terreno. Su presencia es ubicua y logra concentrar toda la información de su gobierno, incluidos los logros de gestión de sus ministros. El presidente que utiliza un sistema cerrado de comunicación reúne todos los focos informativos del gobierno porque tiene una comunicación ministerial totalmente controlada. Sus ministros pueden hablar solo si el presidente les cede la palabra pero no hablan por él ni sin él. Suele estar muy presente en los medios utilizando discursos de enfoque dramatizante, es decir con un estilo de obra teatral, con héroes y villanos narrando causas justas y maldades históricas, a lo que se suma una fuerte cuota de emotividad. 
El discurso, por lo tanto, es casi siempre de batalla, de combate. La construcción de enemigos que legitiman las gestas heroicas de los gobernantes es muy propia de este estilo de comunicación. Podemos decir más: en un esquema de comunicación cerrado el presidente arenga a la ciudadanía como si estuviera en campaña electoral. La comunicación gubernamental se maneja como comunicación electoral, como si el presidente estuviera en campaña permanente y no distinguiera una comunicación de la otra.

El punto más fuerte de esta perspectiva es que todo el material de difusión es de elaboración propia, es muy profuso, se distribuye gratuitamente a todos los medios de comunicación a cambio de resignar que esos medios entren en el espacio en el que habla el presidente. Esto significa que los medios de comunicación independientes no pueden acceder a los actos en los que el presidente se dirige a la opinión pública $y$, mucho menos, plantearle preguntas u objeciones. En esta línea, el uso que tienen de las nuevas tecnologías y de las redes sociales es completamente cerrado: aunque tengan una estética 2.0, se siguen manejando con información de una sola vía. No aceptan cuestionamientos ni feedback de sus interlocutores, por lo que esos gobiernos aplican una lógica de internet 1.0 a su comunicación digital.

Los detractores de la comunicación cerrada sostienen que la debilidad de ese esquema reside en que la falta de debate impone un sistema de gobierno por el cual quien gana las elecciones se considera con derecho a implementar las normas que quiera sin tener en cuenta el punto de vista de la oposición, lo que a su vez genera fuertes resentimientos políticos. Asimismo, las arengas presidenciales fijan la atención de los ciudadanos más en la coyuntura y menos en el largo plazo. Por lo general, esto le resulta más atractivo a la opinión pública, pese a ser menos útil para la información ciudadana (ver tabla 1 ).

Evidentemente, los puntos débiles de un esquema de comunicación son los puntos fuertes del otro. Esto es, el gobierno con comunicación abierta mantiene el diálogo abierto constantemente y es permeable a las críticas y a las propuestas de otros líderes políticos mientras debaten tema de largo alcance. Por su parte, un gobierno con comunicación cerrada se permitirá actuar de manera más contundente, reforzando sus políticas a través de los legisladores que responden a su partido.

Conocer el tipo de comunicación que utiliza cada gobierno permite comprender algunas cuestiones de la dinámica de su gestión. En este sentido la comunicación gubernamental debe suponer una planificación estratégica por la sencilla razón de que es probablemente el ámbito de decisión que interactúa con la mayor cantidad de ciudadanos. Más aun: cada gobierno debe amoldar su sistema de comunicación tanto al estilo del líder como a las características culturales de su país. 


\section{Storytelling}

La idea básica de la comunicación política en general, y de la gubernamental en particular, es relacionar al gobierno con sus ciudadanos. Para ello, se presenta a los líderes de modo tal que los gobernados los consideren no solo confiables a lo largo de toda su gestión sino votables para un siguiente período. ¿Cómo lograr esto? Haciendo que esos ciudadanos se tornen permeables a las palabras de sus gobernantes y para ello es necesario seguir algunas reglas básicas de todo tipo de comunicación y que se aplican de manera evidente a la comunicación corporativa y gubernamental.

1. Lo que una institución pública manifiesta, el modo como lo dice, el momento en el que lo hace, indica algo. Esto es extensivo a los dirigentes políticos en cuyas posturas, gestos, ropa y demás formas de lenguaje no verbal también se puede leer una intención aunque no la tengan.

2. Si no comunicamos, alguien va a comunicar por nosotros. El silencio también comunica: mostramos desinterés por el tema, ignorancia de lo que está ocurriendo o simplemente que no queremos dar entidad a algún asunto. Esto le da oportunidad a otros de opinar por nosotros o de especular acerca de por qué nosotros no opinamos.

3. El mensaje es del receptor, no del emisor. Esto significa que por mucha elaboración de diseño y de discurso complejo que tenga lo que decimos, si no lo hacemos permeable a la audiencia, no es un mensaje eficiente, no cumple su objetivo. Esto lleva a estudiar el modo en el que se redactan las propuestas de gobierno o en el que se describe una nueva política pública.

De esto precisamente se ocupa el storytelling. Se trata de un término inglés cuya traducción podría ser "contar historias". El "contar cuentos" supone una trama sencilla, un lenguaje ameno, un uso de imágenes y metáforas muy conocidas entre los públicos del emisor para despertar empatía y para lograr que quienes escuchen se identifiquen con el narrador. En esta línea, y a modo de antecedente, George Lakoff (1995) explicaba por qué el relato, las metáforas y la apelación a lo moral que hacían los conservadores en los Estados Unidos era tanto más eficiente que el discurso liberal.

Christian Salmon $(2008,2011)$ sostiene que el storytelling comenzó en Estados Unidos, primero de la mano de la comunicación corporativa para luego extenderse a la política en la década de 1990. El autor sostiene que esta narración no busca modificar las convicciones de los ciudadanos - como la propaganda - sino que intenta movilizarla a través de la construcción de relatos, de novelas, de historias con fuerza propia.

Manuel Medrano Marqués (2009) sintetiza esto en la siguiente frase: "Storytelling es en sí el arte de contar historias con un fin comercial, político, moral o religioso. Y 
un arte no es perverso, salvo cuando se hace un uso incorrecto de él", dicho en otros términos, cuando se miente.

Este tema se está tratando en el ámbito académico desde entonces y se ha ido desarrollando de manera consistente. Tanto es así que Luis Arroyo (2012) la nombra en primer lugar dentro de las últimas tendencias en comunicación política. El autor describe el storytelling como "una nueva palabra para el concepto más antiguo: la necesidad de contar y de escuchar historias acerca de nuestra comunidad", "un nuevo modo de describir la vieja necesidad de simplicidad y emocionalidad en política”.

Por su parte, Antonio Núñez (2007) hace un gran aporte explicando cuáles son los relatos que persisten, cuáles se alojan en lo más remoto de los arquetipos antropológicos, por qué y cómo se construye el mito del héroe, logrando brindar un panorama de cómo funciona el storytelling y por qué es tan útil en el discurso político. John Sadowsky y Loïck Roche (2013) se inclinan por el storytelling dentro del ámbito de la gestión corporativa, aclarando también que se trata de un modo de inspiración con liderazgo auténtico. Los autores indican que, para contar historias de manera eficiente, hay que cumplir siete reglas: conocerse muy bien, crear una historia auténtica, involucrar a quienes trabajan con uno, ser uno mismo, proyectar las propias ideas, personalizar las historias y simplificar siempre.

Los mismos Sadowsky y Roche (2013) agregan a estas reglas una lista de las limitaciones y las cuestiones éticas que supone "contar historias". Algunos de estos riesgos son llevar la narración muy lejos, hacer la historia demasiado larga, centrarse mucho en sí mismo, definir mal las fronteras entre la autenticidad, la verdad, la exageración y la manipulación. Otros riesgos son la posibilidad de no hacer bien la personalización, descuidar los detalles de las historias, fallar en la inclusión o fracasar en la encarnación de esa historia en la realidad.

En cuanto al concepto en sí, las investigaciones que tuvieron lugar en español han presentado algunas confusiones a la hora de tratar los términos storytelling y "relato", llegando a tratar ambas palabras de manera indistinta. Orlando D’Adamo y Virginia García Beaudoux (2013) ofrecen una disquisición teórica que aclara este punto. Los autores sostienen que "la construcción de relatos [se hace] mediante la técnica de storytelling o narración de historias con la finalidad poner en marcha estrategias de comunicación política". En otras palabras, el storytelling es una técnica, un recurso narrativo que ayuda a construir el relato. Este relato es, en sí mismo, una estrategia de comunicación con once categorías estructurantes:

1. Conflicto y antagonismo: presentación de un conflicto entre actores antagónicos, lógica amigo-enemigo, uso de esquemas binarios para elaborar justificaciones.

2. Valores: el relato se funda sobre valores generales que sirven luego para enmarcar temas específicos. 
3. Escenificación del liderazgo: señales visuales que orientan al público (colores, lugares, vestimentas, referencias recurrentes, entre otras).

4. Visión: habilidad del líder para definir, conceptualizar y otorgar sentido y dirección a la situación política.

5. Retórica y lenguaje: uso de un lenguaje aspiracional y de una retórica discursiva épica.

6. Mitos: historias ejemplares al servicio de iluminar valores clave.

7. Símbolos: connotan y ornamentan al relato.

8. Líneas argumentales familiares e instaladas en la cultura popular: utilización de tramas y narrativas con fuerte arraigo en la cultura popular que se reciclan a los fines de la comunicación política.

9. Activación de los sentidos: activación simultánea de canales sensoriales (vista y oído).

10. Activación de las emociones: movilización de sentimientos y de identificación afectiva.

11. Moralejas: saber didáctico que se desprende del relato.

A estos avances conceptuales se agrega otro aporte muy novedoso de Carlos Scolari (2009), autor que no solo se interesa por el relato sino que observa también los canales en los que el mensaje se emite, en el que deja en claro que el mensaje debe adaptarse al canal y que debe fluir en simultáneo por diversos canales y con referencias cruzadas entre esas historias, de modo que el público confluya hacia un mismo relato integral y cohesionado. Para explicar esto, toma un concepto de Henry Jenkins quien en 2003 acuñó el término transmedia storytelling. Según Scolari (2009, p. 598), esta confluencia de canales permite construir sentido recurriendo a:

- Microhistorias que se aplican a varios sitios (historietas, videojuegos, videoclips en línea, episodios breves para ser transmitidos por teléfonos celulares (conocidos como mobisodes) y que están muy relacionadas con la macrohistoria que estamos contando.

- Historias paralelas que se desarrollan a la vez que lo hace la macrohistoria. Estas historias paralelas pueden narrar lo que hacen los protagonistas en otros momentos o incluso protagonistas secundarios pero relevantes, y pueden incluso tener secuelas.

- Historias periféricas que tienen menos relación directa con la macrohistoria pero que podrían hacer un aporte. Tal sería el caso de una novela o artículos es- 
critos por los protagonistas que, si bien pueden no contribuir a la historia que está siendo narrada, sí da contexto y contundencia a los conceptos que se vierten en la narración principal.

- Contenidos generados por los usuarios como blogs, wikis, etc.

El storytelling se ha convertido, por lo tanto, en una nueva y prometedora línea de investigación de la comunicación gubernamental.

\section{Comunicación de crisis y de riesgo}

La resolución de una crisis va de la mano de su comunicación, tema clave de las relaciones públicas que también se trasladó a la comunicación de gobierno. Así como algunos autores se dedican a estudiar la relación gobierno-medios de comunicación, las necesidades de la comunicación local o casos emblemáticos de comunicación gubernamental (Elizalde \& Riorda, 2013; Elizalde, Fernández Pedemonte \& Riorda, 2006 y 2011), otros se centraron en el manejo de crisis de gobierno (Elizalde, 2004; Fernández Pedemonte, 2010; Grossman \& Kumar, 1994) o de comunicación de riesgo (Fontana \& Maurizi, 2014).

La comunicación de crisis es netamente un tipo de comunicación reactiva (Noguera, 2005). Se trata de una comunicación que no parte naturalmente del gobierno, sino que este se ve forzado a responder ante una situación planteada por el contexto. La noción básica de crisis supone una situación no habitual — previsible o no-que requiere de atención inmediata y que no se resuelve a través de procedimientos de rutina (Harvard Business Press, 2008; Ruiz Balza \& Coppola, 2011).

Ante una situación de esta naturaleza se busca lograr un manejo estratégico de la información y de las comunicaciones para evitar que amenace y/o lesione la imagen y los atributos de la institución o a la persona a cargo (Harvard Business School, 2008; Ruiz Balza y Coppola, 2011).

Todos los gobiernos sufren crisis mientras dura su gestión. Igual que en el caso de una empresa, el manejo que hace de la comunicación sobre el tema es vital para su imagen. Estas situaciones de crisis, conflictos y escándalos se escapan de los sistemas de comunicación corrientes basados en el control porque el disenso social es, por definición, entrópico e imprevisible. Dice Luciano Elizalde que "la necesidad de manejar racionalmente situaciones de disenso violento es cada vez mayor" (Elizalde, 2011, p. 97) porque este se estableció como mecanismo de cambio político.

La comunicación de riesgo, en cambio, es proactiva. Supone una política pública planificada, pautada estratégicamente y permeable a todos los estratos de la sociedad. Esta política permite a los ciudadanos anticiparse a situaciones de catástrofes naturales. Fontana y Maurizi explican con gran claridad las características de este tipo de 
comunicación. Los autores sostienen que "la gestión del riesgo de desastres es un paradigma que viene tomando fuerza desde la década de los 90, especialmente cuando los principales organismos internacionales pusieron en el centro de atención de los jefes de Estado del mundo el tema de la reducción de riesgos de desastres..." (Fontana \& Maurizi, 2014, p. 9). Con este ejercicio de comunicación, al brindarles anticipadamente indicaciones sobre qué hacer en caso de terremoto, inundaciones, incendio o incluso epidemias, un gobierno puede reducir la incertidumbre de las personas afectadas por catástrofes. Si esta política preventiva se acompaña con una gestión concreta de la emergencia, el ciudadano sabrá qué hacer y sentirá todo el apoyo de las autoridades en esa situación de impotencia ante un desastre natural.

\section{Nuevos canales}

Desde sus orígenes hasta la fecha toda la comunicación política, tanto electoral como gubernamental, hizo fuerte hincapié en el análisis de los canales y piezas comunicacionales utilizados para llegar al ciudadano (Maarek, 1997; De Masi, 2001; Gergen, Lewis \& Izurieta, 2005; Izurieta, Arterton \& Perina, 2005; Elizalde, Fernández Pedemonte \& Riorda, 2006 y 2011; Elizalde \& Riorda, 2013; Ponce \& Rincón, 2013). En esos estudios se analizaron posters, spots, anuncios en los periódicos, publicidad en las radios, incluso discursos.

Sin embargo, las (ya no tan) nuevas tecnologías han dado lugar a un cambio de paradigma, potenciado al infinito con la incorporación de esas plataformas a las redes sociales. Internet se hizo genuinamente global alrededor de 1995. En ese momento las páginas web tenían formato 1.0: solo emitían información. Por aquel entonces pocas empresas, medios y gobiernos utilizaban estos canales, pero en muy pocos años todas las instituciones sin falta se volcaron a publicar sus contenidos y ofertas en internet. Comenzaron como sitios web, pasaron a ser blogs, de allí al chat y los programas de mensajería instantánea, hasta que la lógica de la web cambió para convertirse en web 2.0.

En ese contexto el público pasó a tener poder; pudo producir información y postearla en el ciberespacio; los teléfonos se volvieron inteligentes y la cantidad de información en forma de datos e imágenes se multiplicó por cifras impensables. En ese contexto se crearon plataformas como Facebook, Twitter, Flikr, Instagram, Snapchat, en las que las conversaciones son horizontales y donde se dan los nuevos debates sociales y nuevas formas de interacción con el ciudadano (Gutiérrez-Rubí, 2014 y 2016; Gutiérrez-Rubí \& Peytibi, 2016).

No hay político que pueda quedar fuera de esto, del mismo modo que no hay empresa que no tenga un community manager o un medio de comunicación o periodista que no adquiera información en estos ámbitos. Lila Luchessi sostiene que las redes 
sociales siempre existieron pero que son las plataformas digitales las que las potenciaron al máximo, permitiendo instantaneidad en la difusión de la información y acceso a individuos con los cuales no nos podríamos contactar de otro modo (Luchessi \& Videla, 2016).

Este esquema de contactos es invaluable para la política. Aquellos dirigentes que no ven el cambio y que se ciñen a estrategias enteramente territoriales pierden votos. Si bien una cosa no reemplaza a la otra porque de lo digital no se vive solamente, es esencial comprender que la estrategia digital complementa la cobertura que una campaña puede hacer en el territorio físico.

Hay nuevas formas de medir - y en ocasiones, de anticipar- el devenir de los votos; entre ellas, la que llevan adelante los observatorios de las redes. Quienes pueden acceder a los grandes datos que almacenan empresas como Facebook, Twitter o Snapchat y quienes saben medir con precisión cómo se mueven, aglutinan y desarticulan las comunidades digitales, están en posición de anticipar resultados electorales incluso mejor que los encuestadores. En este sentido, y solo a modo de ejemplo, basta citar el Observatorio de Redes que conforma el grupo de investigación sobre coaliciones con base en la carrera de Ciencia Política (Universidad de Buenos Aires), apoyado por la asociación civil CIPPEC. Ellos definen "red" como una conexión entre dos o más elementos que produce distintos tipos de interacciones. Estas conexiones construyen mapas. Y esos mapas ayudan a entender la política. De este modo, proponen aplicar el análisis de redes a distintos fenómenos de la actividad política. Observamos las relaciones entre los actores políticos en distintos ambientes de interacción institucional (el congreso, una elección, dentro de una coalición) y mediática (Facebook, Twitter, etc.), para evaluar cómo actúan: qué hacen, qué dicen, con quiénes se vinculan, a quiénes se acercan, con quiénes se enfrentan, cómo votan y cómo reaccionan (Clerici, Cruz \& Goyburu, 2016).

\section{Otros temas analizados}

Más allá de los asuntos mencionados, la comunicación gubernamental o comunicación de gobierno ha centrado su atención en algunas cuestiones más.

\section{Gobierno y medios de comunicación}

Tal vez el más importante de ellos sea la relación entre el gobierno y los medios de comunicación masiva. En la actualidad muchos gobiernos latinoamericanos dedican grandes recursos a la producción de contenidos mediáticos a la vez que desconocen la intermediación del periodismo (Rincón, 2008; Amado \& Amadeo, 2012 y 2014). Contrariamente a lo que es la gestión tradicional de prensa, se descarta la construcción 
de un vínculo entre los periodistas y las autoridades. Tradicionalmente el gobierno fomenta y facilita el acceso de los periodistas a los funcionarios y brinda conferencias de prensa de forma regular (Starke \& Amadeo, 2010).

El celo con que se manejan las apariciones oficiales alrededor de temas favorables hace que en muchas ocasiones se prohíba el ingreso de otro reportero que no sea la agencia oficial. En esos casos se evita cualquier pregunta periodística y la selección de las buenas noticias que serán producidas y distribuidas a todo el sistema de medios queda a criterio del secretario de comunicación (Amadeo, Amado \& Aruguete, 2013).

Con restricciones para acceder a los eventos o a la información pública, la prensa queda reducida a una mera repetidora de las gacetillas e imágenes oficiales e incide en la información que reciben los ciudadanos. Esto acota las perspectivas con las que cuenta el ciudadano para opinar sobre política y afecta la calidad de la cultura política de esa comunidad (Amadeo \& Amado, 2013). directamente la calidad de la información. A ello se suma el manejo discrecional de la pauta publicitaria, que favorece a los que se identifica desde el gobierno como "periodistas militantes" en detrimento de los que se acusa de "periodistas opositores" (Amado, 2011, p. 32). Eso genera grupos que manejan la información pública con criterios contrapuestos y propicia un clima de autocensura en la medida en que las coberturas desfavorables despiertan represalias desde el gobierno.

\section{Comunicación local}

A estas líneas de investigación se suma otra igualmente importante y sumamente visible: la comunicación local. En la actualidad, de hecho, nadie cuestiona que los ayuntamientos constituyen una de las administraciones más dinámicas e innovadoras de todo el sector público. Políticos y directivos locales se enfrentan cada día al noble fin de gestionar e implantar bienes, servicios e infraestructuras públicas. Con un lenguaje claro, estilo ameno y contenido extraordinariamente práctico, varios autores abordan aspectos de la planificación política, los programas de gobierno, la comunicación e información municipal, las habilidades o los principios más relevantes en el funcionamiento de las principales áreas municipales (Organización de Consultores Políticos Latinoamericanos, 2008; Fundación Konrad Adenauer, 2008; Asensio Romero, 2006).

\section{Política pop}

La más reciente línea de investigación, en creciente auge, es la que plantea la identificación de la comunicación gubernamental con algún fenómeno televisivo. Omar Rincón y otros autores logran asociar la comunicación de los presidentes latinoamericanos a telenovelas, stand ups, reality shows, talk shows, espectáculos musicales o de- 
portivos y demás subgéneros. Cada acción de comunicación presidencial personalizada se torna un evento similar al que podría dar una estrella de rock o un deportista reconocido (Amado, 2016; Riorda \& Rincón, 2016; Rincón, 2008). La comunicación gubernamental es tratada como si la política hubiera adoptado la forma estética de la cultura pop (Amado, 2016).

\section{Nueva comunicación, ¿nueva política?}

Ante tantos abordajes teóricos y empíricos de la comunicación gubernamental debemos poner atención en las nuevas formas que está tomando la comunicación gubernamental.

Esta nueva comunicación política, tan basada en la comunicación institucional proveniente del sector privado, ¿está dando lugar a una nueva política o solo cambian las formas para que el fondo permanezca igual?

Poco a poco la comunicación ciudadana se va sumando a la comunicación gubernamental tradicional, entendida como aquella comunicación emitida exclusivamente por el Poder Ejecutivo, haciendo que el futuro de la comunicación de gobierno deba pensarse de manera más horizontal, participativa y abierta. En este sentido, Josep Rota llega a hablar de una comunicación "participativa, abierta, democrática, multidireccional, horizontal, descentralizada e integradora” (Rota, 1996, p. 1).

En la última década y de modo paulatino la concepción que el ciudadano tiene de sí mismo ha ido cambiando así como también su idea de qué significa la ciudadanía. El ciudadano va asumiendo un papel menos pasivo y cada vez más dueño de su lugar en la comunidad. Es de esperar que los gobiernos comiencen también a cambiar la concepción que tienen de su interlocutor.

Adriana Amado insiste en que todavía falta mucho para entender que en la comunicación de gobierno el protagonista es el ciudadano y que en segundo lugar deben estar las instituciones, no el partido de gobierno ni el político que gestiona. Ante la comunicación vertical y la clausura de los canales tradicionales de diálogo, los ciudadanos intensifican su comunicación horizontal, fuera del circuito formal, a través de las redes sociales y de las acciones en su comunidad (Amado, 2014).

En este sentido, Rota sostiene que "la voz de la sociedad civil es escuchada poco por los administradores públicos, y que su enorme energía potencial puesta al servicio de la solución de los problemas que la afectan, la cual constituye gran parte de la razón de ser del gobierno, es desperdiciada" (Rota, 1996, p. 1).

Por esto, agrega el autor, que los ciudadanos tienen baja participación en la administración pública, no contribuyen en la solución de problemas, dan lugar a una ciudadanía pasiva y poco solidaria, caracterizada por su sentido de impotencia y alienación. Esta situación genera necesariamente una creciente pérdida de credibilidad y confian- 
za en el gobierno que lleva al desarrollo de una relación antagónica entre el gobierno y la ciudadanía, la cual considera su relación con el gobierno y los servidores públicos como "nosotros contra ellos" en lugar de "nosotros y ellos colaborando conjuntamente en la solución de los problemas que nos afectan".

Las nuevas reglas de juego de la comunicación suponen una relación más pareja. Ni las empresas desde su comunicación corporativa ni la administración pública desde su comunicación gubernamental escapan a estas tendencias. La comunicación de gobierno debe tener en cuenta al ciudadano. En los últimos años, la comunicación gubernamental cambió mucho y se destacan algunas ventajas y desventajas. Entre las primeras se cuenta, por ejemplo, con el hecho de que todos los gobernantes comprenden que la comunicación ya es parte de la gestión política y merece un tratamiento especial. Entre las desventajas está que los gobernantes asocian esa comunicación gubernamental a la comunicación electoral que les permitió asumir el cargo que ejercen. Esto les impide despegarse de los objetivos de imagen y legitimación personal en lugar de dedicarse a rendir cuentas como parte de su compromiso con una gestión transparente (Amado, 2014).

En pocas palabras, una comunicación gubernamental que olvida a sus ciudadanos desperdicia la energía potencial de millones de individuos que podrían ayudar a resolver problemas de la administración pública. Según Rota (1996), la solución es compleja pero factible y no supone que el gobierno abandone su papel de diseminador de información, sino que a esta función agregue otros recursos comunicacionales.

Este modo de gestionar la comunicación gubernamental, como si se tratara de una organización que busca legitimar su imagen perpetuamente, representa una ventaja para el poder de turno y podría lesionar la igualdad de fuerzas del juego democrático.

Este modo de gestionar la comunicación gubernamental, como si se tratara de una organización que busca legitimar su imagen perpetuamente, representa una ventaja para el poder de turno frente a la oposición, lo que podría lesionar la igualdad de fuerzas del juego democrático. Más aun, se centra en el individuo que gobierna antes que en las instituciones de gobierno, lo que genera una tergiversación en las nociones básicas de cultura política democrática.

La debilidad reside en que los tiempos y espacios de la comunicación no son los de la política. Dominique Wolton (1998) sostiene que hasta ahora el abordaje de la comunicación política se hacía desde los medios. El desarrollo de un modelo de comunicación más cercano a la comunicación corporativa convierte al gobierno en un emisor principal del sistema y por decisión propia, no por exigencia de los medios, prioriza la comunicación por sobre la gestión (Amado \& Amadeo, 2012).

Hemos recorrido los conceptos de comunicación gubernamental, sus definiciones y funciones. Analizamos su papel clave en la legitimidad del sistema democrático 
y en el proceso electoral. Vimos, asimismo, que las investigaciones especializadas en comunicación gubernamental se abocan a las técnicas utilizadas, a la clasificación de los estilos, al estudio de casos tanto nacionales como municipales, a la relación entre los poderes políticos y los medios de comunicación masiva, al storytelling y a la resolución de situaciones de crisis. Queda pendiente establecer un tema clave: la relación entre cultura política y comunicación gubernamental, pero eso será tema de futuras investigaciones.

\section{Referencias}

Amadeo, B. (2014). Tipología de la comunicación gubernamental: el caso de la Argentina democrática. En: D’Alessandro, M. O. (ed.). Liderazgo presidencial y política partidaria en Argentina: nación y provincias (1983-2007) (p. 83-124). Buenos Aires, EUDEBA.

Amadeo, B. \& Amado,A. (2013).El periodismo frente a la comunicación gubernamental: condicionamientos oficiales a la tarea periodística. Revista Opera, 13, p. 4158. Disponible en: http://revistas.uexternado.edu.co/index.php/opera/article/ view/3764/3910 [consultado: 14 septiembre 2016].

Amadeo, B.; Amado, A. \& Aruguete, N. (2013). Comunicación "Modelo K": KirchnerKirchner 2005-2011. En: Ponce, M. \& Rincón, O. (eds.). Caudillismo, e-política y teledemocracia:comunicación de gobierno en América Latina (p.19-38). Montevideo: Fin de Siglo; Universidad Católica del Uruguay. Centro de Competencia en Comunicación.

Amado, A. (ed.) (2010). La palabra empeñada. Buenos Aires: Fundación Ebert.

Amado, A. (2011). Prensa y gobierno en situaciones complejas. En: Elizalde, L.; Fernández Pedemonte, D. \& Riorda, M. La gestión del disenso: la comunicación gubernamental en problemas (p. 287-322). Buenos Aires: La Crujía Ediciones.

Amado, A. (2014). La comunicación pública como espectáculo. Buenos Aires: Konrad Adenauer Stiftung.

Amado, A. (2016). Política pop: de líderes populistas a telepresidentes. Buenos Aires: Ariel.

Amado, A.; Amadeo, B. (2012). Cristina al gobierno: las relaciones públicas al poder. En: XI Congreso de la Asociación Latinoamericana de Investigadores en Comunicación (ALAIC), 9 al 11 de mayo de 2012, Montevideo [No editado].

Amado, A.; Amadeo B. (2014). Las relaciones públicas al poder: el caso de la Argentina en el siglo XXI. En: Amado, A. (ed.). La comunicación pública como espectáculo: relatos de la Argentina del siglo XXI (p. 68-151). Buenos Aires: Konrad Adenauer Stiftung.

Amado, A. \& Castro Zuñeda, C. (1999). Comunicaciones públicas: el modelo de la 
comunicación integrada. Buenos Aires: Temas.

Arroyo, L. (2012). The latest trends in political communication, conferencia dictada en el IE School of Communication, Madrid, 31 de mayo de 2012. Disponible en: http:// www.luisarroyo.com/wp-content/uploads/2012/06/The-latest-trends-in-politicalcommunication.pdf [consultado: 14 septiembre 2016].

Asensio Romero, P. (2006). El libro de la gestión municipal: claves de éxito para políticos $y$ directivos locales. Madrid: Díaz de Santos.

Canel, M. J. (1999). Comunicación política: técnicas y estrategias para la sociedad de la información. Madrid: Tecnos.

Canel, M. J. (2007). Comunicación de las instituciones públicas. Madrid: Tecnos.

Canel, M. J. \& Sanders, K. (2010). Para estudiar la comunicación de los gobiernos: un análisis del estado de la cuestión. Comunicación y sociedad (Navarra), 23 (1), p. 7-48.

Chaves, N. (2011). La marca-país en América Latina. Buenos Aires: La Crujía Ediciones. Clerici, P.; Cruz, F. \& Goyburu, L. (2016). No todo es territorio: las elecciones argentinas 2015 en las redes sociales. [inédito].

D’Adamo, O. \& García Beaudoux, V. (2013). Arquitectura del relato político. Storytelling al servicio de la comunicación política. En: Crespo, I. \& Rey, J. del (eds.). Comunicación política y campañas electorales en América Latina. Buenos Aires: Biblos.

De Masi, Oscar (comp.) (2001). Comunicación gubernamental. Buenos Aires: Paidós.

Domenach, J. M. (1986). La propaganda política. Buenos Aires: EUDEBA.

Elizalde, L. (2004) Estrategias en las crisis públicas. Buenos Aires: La Crujía Ediciones.

Elizalde, L. (2011). Confusión y enfrentamiento: mediatización y disenso en el gobierno de Cristina Fernández de Kirchner. En: Elizalde, L; Fernández Pedemonte, D. \& Riorda, M. (eds.). La gestión del disenso: la comunicación gubernamental en problemas. Buenos Aires: La Crujía Ediciones.

Elizalde, L.; Fernández Pedemonte, D. \& Riorda, M. (2006). La construcción del consenso: gestión de la comunicación gubernamental. Buenos Aires: La Crujía Ediciones.

Elizalde, L.; Fernández Pedemonte, D. \& Riorda, M. (2011). La gestión del disenso: la comunicación gubernamental en problemas. Buenos Aires: La Crujía Ediciones.

Elizalde, L. \& Riorda, M. (2013). Comunicación gubernamental 360. Buenos Aires: La Crujía Ediciones.

Fernández Pedemonte, D. (2010). Conmoción pública: los casos mediáticos y sus públicos. Buenos Aires: La Crujía Ediciones.

Fontana, S. \& Maurizi, V. (eds.) (2014). Comunicando el riesgo. Buenos Aires: Biblos.

Fundación Konrad Adenauer (2008). Comunicación política municipal. Diálogo político, (2008: 1), p. 9-179. 
Gergen, D.; Lewis, A. \& Izurieta, R. (2005). Cambiando la escucha: comunicación presidencial para ciudadanos indiferentes. Buenos Aires: La Crujía Ediciones.

Grossman, M. \& Kumar, M. J. (1994). Conflict and cooperation. En: Davis, R. Politics and the media (p. 236-241). New Jersey: Prentice Hall.

Gutiérrez-Rubí,A.(2014). Tecnopolítica: el uso y la concepción de las nuevas herramientas tecnológicas para la comunicación, la organización y la acción políticas. [Barcelona: edición del autor]. Disponible en:

http://www.gutierrez-rubi.es/wp-content/uploads/2014/11/Tecnopol\%C3\%ADtica. pdf [consultado: 14 septiembre 2016].

Gutiérrez-Rubí, A. (2016). La transformación digital y móvil de la comunicación política. Barcelona: Fundación Telefónica; Ariel. Disponible en:

http://www.fundaciontelefonica.com/arte_cultura/publicaciones-listado/paginaitem-publicaciones/?itempubli=334 [consultado: 14 septiembre 2016].

Gutiérrez-Rubí, A. \& Peytibi, X. (2016). Snapchat en política. Barcelona: We, Observatorio de la Comunicación Social. Disponible en: http://www.gutierrezrubi-es/snapchat-en-politica/ [consultado: 14 septiembre 2016].

Heclo, H. (2000). Campaigning and governing: a conspectus. En: Ornstein, N. J. \& Mann, T. E. (eds.). The permanent campaign and its future (p. 1-37). Washington DC: American Enterprise Institute; The Brookings Institution.

Izurieta, R.; Arterton, Ch. \& Perina, R. (2005). Estrategias de comunicación para gobiernos. Buenos Aires: La Crujía Ediciones.

Lakoff, G. (1995). Metaphor, morality, and politics or, why conservatives have left liberals in the dust. Social research, 62 (3), p. 177-213.

Luchessi, L. \& Videla, L. (comps.) (2016). Desafíos del periodismo en la sociedad del conocimiento: discusiones a partir del tercer Seminario Brasil-Argentina de pesquisa em jornalismo (BAPIJOR). Viedma: Universidad Nacional de Río Negro.

Maarek,P.(1997). Marketing político y comunicación: claves para una buena información. Barcelona: Paidós Ibérica.

Medrano Marqués, M. (2009). Storytelling, el arte de narrar al servicio de la política. En su: Blog cultural, 26 de abril de 2009. Disponible en:

http://manuelmedrano.wordpress.com/2009/04/26/storytelling-el-arte-de-narrar-alservicio-de-la-politica/ [consultado: 14 septiembre 2016].

Minutella, I. P. (2010). La comunicación de gobierno. Reflexión académica en diseño y comunicación, 11 (14), p. 141-145.

Noguera, F. (2005). La campaña permanente. En: Izurieta, R.; Arterton, C. \& Perina, R. Estrategias de comunicación para gobiernos. 3a. ed. (p. 77-101). Buenos Aires: La Crujía Ediciones. 
Núñez, A. (2007). ¡Será mejor que lo cuentes!: los relatos como herramienta de comunicación: storytelling. [Barcelona]: Empresa Activa.

Organización de Consultores Políticos Latinoamericanos (OCPLA) (2008). Comunicando desde la identidad: manual de comunicación politica local. Buenos Aires: Fundación Konrad Adenauer.

Ornstein, N. J. \& Mann, T. E. (eds.) (2000). The permanent campaign and its future. Washington: American Enterprise Institute; The Brookings Institution.

Ponce, M. \& Rincón, O. (eds.) (2013). Caudillismo, e-política y teledemocracia. Montevideo: Fin de siglo.

Public Relations Society of America (2012). About public relations. Disponible en: http://www.prsa.org/aboutprsa/publicrelationsdefined/ [consultado: 14 septiembre 2016].

Pye, L. W. (1991). Political communication. En: Bogdanor V. (ed.). The Blackwell encyclopaedia of political science. (p. 442-445). Oxford: Blackwell.

Rincón, O. (ed.) (2008). Los tele-presidentes: cerca del pueblo, lejos de la democracia: crónicas de 12 presidentes latinoamericanos y sus modos de comunicar. Bogotá: Friedrich Ebert Stiftung. Centro de Competencia en Comunicación para América Latina.

Riorda, M. (2006). Hacia un modelo de comunicación gubernamental para el consenso. En: Elizalde, L.; Fernández Pedemonte, D. \& Riorda, M. La construcción del consenso: gestión de la comunicación gubernamental (p. 17-142). Buenos Aires: La Crujía Ediciones.

Riorda, M. (2011). Gestionando certidumbres: la comunicación de crisis no es comunicación gubernamental, electoral ni de riesgo. En: Elizalde, L.; Fernández Pedemonte, D. \& Riorda, M. La gestión del disenso: La comunicación gubernamental en problemas (p. 7-44). Buenos Aires: La Crujía Ediciones.

Riorda, M. \& Rincón, O. (eds.) (2016). Comunicación gubernamental en acción. Buenos Aires: Biblos.

Rota, J. (1996). Comunicación, gobierno y ciudadanía. Revista del CLAD: reforma $y$ democracia, 5 Disponible en http://old.clad.org/portal/publicaciones-delclad/revista-clad-reforma-democracia/articulos/005-enero-1996/0026801.pdf [consultado: 14 septiembre 2016].

Ruiz Balza, A. \& Coppola, G. (2011). Gestión de riesgo comunicacional: issues management. Buenos Aires: La Crujía Ediciones.

Sadowsky, J. \& Roche, L. (2013). Las siete reglas del storytelling. Buenos Aires: Granica. Salmon, C. (2008). Storytelling: la máquina de fabricar historias y formatear las mentes. Barcelona: Península. 
Salmon, C. (2011). La estrategia de Sherezade: apostillas a Storytelling. Barcelona: Península.

Scolari, C. A. (2009). Transmedia storytelling: implicit consumers, narrative words, and branding in contemporary media production. International journal of communication, 3, p. 586-606.

Solís Delgado, J. J. (2010). Comunicación gubernamental... ¿eficaz?”. Razón y palabra. Disponible en:

http://www.razonypalabra.org.mx/Intersticios/intersticio_2010/intersticio_3.html [consultado: 14 septiembre 2016].

Starke, R. \& Amadeo, B. (2010). Comunicación gubernamental: la presidencia de Néstor Kirchner". Journal of PR, Buenos Aires: Consejo Profesional de Relaciones Públicas de la República Argentina, 1, p. 41-59.

Swanson, D. L. (2003). El campo de la comunicación política: la democracia centrada en los medios. En: Muñoz-Alonso, A. \& Rospir, J. I. (eds.). Comunicación política. Madrid: Universitas.

Winocour, R. (2000). Comunicación política. En: Baca Olamendi, L. et al. (comps.). Léxico de la política. México: Fondo de Cultura Económica.

Wolton, D. (1998). Las contradicciones de la comunicación política. En: Gauthier, G., Gosselin, A. \& Mouchon, J. Comunicación política. Barcelona: Gedisa. 